\title{
COMPUTERIZED INTEGRATED PROJECT MANAGEMENT SYSTEM FOR A MATERIAL PULL STRATEGY
}

\author{
Sang-Chul KIMa, Yong-Woo KIM ${ }^{\mathrm{b}}$ \\ ${ }^{a}$ Department of Architectural Engineering, Hanbat National University, Deajeon Korea \\ ${ }^{b}$ College of Built Environment, University of Washington, Seattle, WA
}

Received 11 Feb 2012; accepted 05 Nov 2012

\begin{abstract}
The purpose of this paper is to present a computerized integrated project management system and report results of a survey on the effectiveness of the system. The system consists of a scheduling system, material management system, labor/equipment system, and safety/quality control system. The backbone system is a scheduling system that adopts a production planning system and a project scheduling system. The lowest level in the scheduling system is a daily work management system, which is linked to each functional management system (i.e. material management system, labor/equipment system, and safety/quality control system). The paper focuses on the material management and scheduling systems to implement a material "pull" system to reduce material inventories on site. Details of material management and scheduling systems are discussed, and a sample application is presented to demonstrate the features of the proposed computer application system. The paper presents practitioners and researchers with a practical tool to integrate material management and scheduling systems for site personnel.
\end{abstract}

Keywords: daily work management, material management system, lean construction, integrated system.

\section{Introduction}

The development of computer and information technology has helped the construction industry meet increasingly complex challenges (Paulson 1995). One of these important challenges involves production control. Production control is usually referred to as a set of activities concerned with planning and controlling all aspects of production including material management and scheduling. Production control consists of aggregate production planning, material coordination, work load control, work order release, and production unit control (Bertrand et al. 1990). Production control in this paper is focused on production work planning (or work order release) and material ordering. Computerized management systems have been developed to improve production control in the construction industry. As a result, computerized management systems such as the scheduling or material procurement system have been used by contractors, construction managers, and site managers among others. Material management is one of the key management issues because material costs components account for more than $50 \%$ in almost every construction company (Asplund, Danielson 1991; WegeliusLehtonen et al. 1998).

Construction material management requires more than a single project control function. A project schedule management system needs to be linked to the material procurement and inventory control systems. If a project pursues a material pull system, in which materials are deli- vered based on the actual needs onsite, a project schedule needs to be established and integrated into the detailed production plan (Ballard et al. 2007). To minimize material inventories onsite, close coordination between production planning and schedule management is required (Tommelein 1998). Therefore, pull-based material management requires a comprehensive project management system rather than a stand-alone functional system.

The purpose of this paper is to present a computerized project management system that links the material management system to a detailed production plan (i.e. daily work management plan). It also seeks to report the results of the survey conducted to measure the effectiveness of the system. The system adopts lean construction principles such as reliable production planning and material pull strategy (Ballard, Kim 2007). It also uses mobile technology, which allows each stakeholder to share information in real time.

The first part of this paper describes the daily work management and material procurement systems. The backbone system is a schedule management system that adopts material production planning as well as project scheduling.

The system architecture is presented, followed by a prototype material management system coupled with a daily work management system. A pilot project to demonstrate the proposed system is then presented. The pilot test demonstrates the feasibility of the system onsite. 
The researchers conducted a survey to validate the proposed system's effectiveness. The survey result shows the potential benefits of the proposed system.

\section{Related works}

\subsection{Material management system}

The literature on construction material management includes inventory control matters such as just-in-time (JIT) delivery, site material management, and material tracking technology. Research on the inventory system, especially JIT delivery, was conducted as the lean concept was applied to construction work (Ballard 2000). The development of information technology provided seeds for progress in the area of site material management. Traditionally, the industry prefers a material "push" strategy, in which materials are released according to a procurement plan regardless of whether or not the downstream process is ready to process them (Lean Construction Institute 2011). It is not difficult to find cases where materials are ordered and stocked onsite for more than three weeks (Kim et al. 2007), but the construction industry is gradually recognizing the importance of minimizing material inventories (Arbulu et al. 2003). As a result, some companies tried to implement JIT delivery or reduce their material inventories onsite (Ballard et al. 2007). Both JIT delivery and reducing material inventories require a "pull" system, where a request from the internal customer who uses the material signals that the material is needed, as opposed to a "push" system, where material production orders are released based on a central schedule regardless of whether or not the downstream process is ready to process them (Lean Construction Institute 2011). A push system does not work when the production system turns out to be unreliable (i.e. not conforming to the schedule). On the other hand, an order signal to a supplier in a pull system is based on the system status that determines whether a release is allowed or not (Hopp, Spearman 1996), which justifies the development of a comprehensive project management system. This system features a detailed production plan that is linked to the material purchasing and inventory control systems.

Researches on tracking, locating, finding, and distributing the right material for the right location at the right time have been conducted since prefabrication and preassembly have prevailed in the industry over the past 15 years (Haas et al. 2000). The areas in this domain include: (1) automatically tracking the locations of the construction agents, laborers, and equipment; (2) identifying and determining the status of the basic activity that the agent is engaged in; and (3) deriving project performance indicators. Jang et al. (2008) presented a new prototype framework of automated tracking and monitoring system for construction materials with the $\mathrm{ZigBee}^{\mathrm{TM}}$ protocol.

Another research trend related to material management system involves Supply Chain Management (SCM). SCM had strength in actual distribution and delivery operations (Forrester, Senge 2001). Pserng et al. (2006) proposed a supply chain model in the construction indust- ry for minimizing total inventory cost, and creating a decision-support system for raw material suppliers, owners, and steel factories. Sobotka and Czarnigowska (2005) presented a Supply Chain Operations Reference model (SCOR model) while Pan et al. (2011) proposed SIMPROCESS to explore the behavior of the construction supply chain process and to develop a performance evaluation method.

GPS, RFID, bar code, and PDA have been used in the material management system. Kim et al. (2011) adopted RFID, while the ZigBee protocol was tested in an indoor environment for monitoring construction material. RFID was used in another research (Moon, Yang 2010) to improve communications during concrete pouring operations.

The literature review conducted in line with this study demonstrated a need for a comprehensive project management system that couples the material management system with a detailed production plan to implement a material pull strategy. This paper presents not only a prototype project management system for material pull management, but also the results of a survey that was conducted on the prototype's effectiveness.

\subsection{Production planning}

Matching the load with capacity is critical in ensuring productivity of the production systems in construction (Ballard 2000; Thomas, Horman 2006). According to Ballard (2000), load is the amount of work in a specified time assigned through planning to crews, while capacity is the amount of work that a crew can do at any point in time with the tools, work methods, and conditions available onsite. Production control, which is different from project control, was introduced into construction with LPS (Ballard 1994). The primary rules or principles for production control are as follows (Ballard, Kim 2007):

-Drop activities from the phase schedule into a sixweek (typical) look-ahead window, screen for constraints, and advance only if the constraints can be removed in time;

- Try to make only quality assignments that meet quality criteria (i.e. soundness, sequence, and size) for release to the customer process in order to remove the uncertainties of "assignment" (Ballard 2000). Reject any defective assignments that do not meet the criteria;

- Track the percentage of assignments completed in each plan period (percent plan complete, PPC), and act on the reasons for plan failure.

LPS produces quality tasks throughout the makeready and shielding processes. Generating quality tasks shields production units from workflow uncertainty by enabling such units to improve their own productivity, and also by improving the productivity of the units downstream (Ballard, Howell 1998). In lean community, flow variation and how they affect construction project performance have been studied by many researchers (Ballard et al. 2007; Ballard 2002; Gonzalez et al. 2008; Sacks et al. 2009). Liu et al. (2011) found that work flow variation and labor productivity are related in const- 
ruction practice. The LPS proposes that the SHOULD needs to be adjusted to the current realities, and that the look-ahead and weekly planning must be further adjusted to what CAN and WILL be done (Ballard 2000). Kim and Ballard (2011) showed that the LPS theoretically supports the concept of "pull". The scheduling system, which is described in the next section, adopts the LPS to improve planning reliability and to increase the length of planning of the look-ahead window in line with the demand for the implementation of a material pull system. In a proposed system, a daily work management system is used to apply the LPS to generate quality assignments to increase planning reliability, which enables users to pull materials.

\section{System architecture}

General contractors (GCs) are likely to concentrate on the master schedule and project costs rather than on detailed production planning. However, managing different specialists requires the coordination of their production planning, which encompasses operational details related to their work schedule. They are very challenging tasks for the GC site personnel due to the limited resources available (e.g. number of site personnel).

Figure 1 shows the system architecture made up of multiple management modules. The proposed computer application system integrates a scheduling system (daily work management system) with a material management system, a manpower/equipment management system, and safety/environment/quality information. Mobile technology allows information on the scheduling system to be communicated along with information on other systems on an as-needed basis. If a contractor pursues a minimum level of material inventory, a site manager must have a reliable detailed schedule so as to reduce the order quantity. Therefore, a reliable daily work management plan should be communicated with the subcontractors and suppliers.

\subsection{Material management module}

The Just-in-Time inventory system focus is having the right material, at the right time, at the right place, and in the exact amount (Hopp, Spearman 1996). The site material manager calculates the right amount of material for the tasks. For timely delivery, the daily work management system shields the uncertainties of assignments, enabling pull-based request for materials according to the updated look-ahead schedule. Finally, for the right place, the bar code and radio frequency identification (RFID) reader are used to manage the shipment of materials. To enable timely delivery of steel rebar, a rebar processing plant was established. The details regarding this module are presented in the "Material Procurement System" section.

The system, in which detailed work planning is critical, requires collaboration with the subcontractors. All subcontractors must use this system to carry out construction work. Payment is also made via the system.

The subcontractors in this study, as shown in Figures $4-7$, use the same screen for task setting and meeting in addition to the managing schedule and construction costs, manpower, and materials, via a PDA.

\section{Scheduling system: implementation of daily work management}

The scheduling system is the backbone subsystem in the proposed system. It consists of a master schedule, a fourweek look-ahead schedule, task setting, task meeting/daily work release, daily payment, planning reliability, and cause analysis. The system follows the Last Planner System (LPS), which uses a shielding process (i.e. making quality assignment) to remove the uncertainties of the assignments as described in the production control section. The first step in the application is the development of a master schedule (see "1. Master Schedule"). For this purpose, the data from past similar construction projects are used. The site manager can retrieve

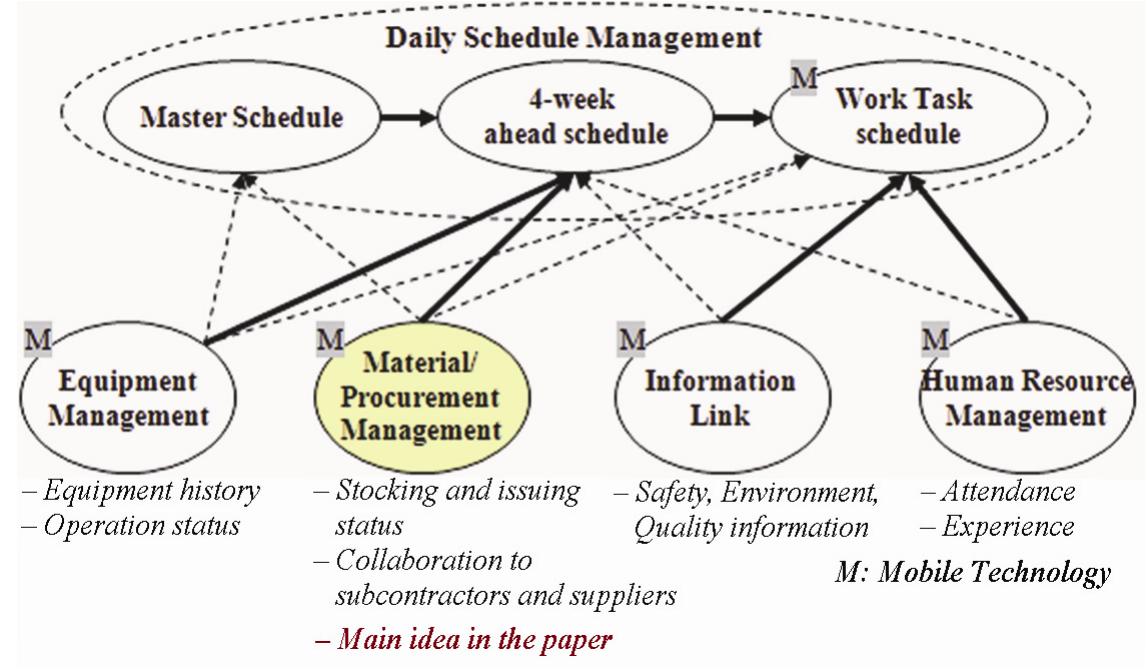

Fig. 1. System architecture 
the previous master schedules with specific conditions including commercial, residential, or road projects. After a master schedule is made, the detailed activities (e.g. work breakdown structure, WBS) and costs (e.g. cost breakdown structure, CBS; unit price; materials) are to be prepared. Both WBS and CBS are referred to in the previous construction data, and they are modified for the project (see "2. Four-Week Look-ahead Schedule"). Once the detailed activities are fixed, the task schedule from the detailed activities shall be created by all the participants, field engineers, construction managers, site manager and subcontractors (see "3. Task Setting"). Subsequently, the daily work shall be checked and approved in a task meeting (see "4. Task Meeting") based on the task schedule. The governing rule in checking and approving detailed tasks shall be "shielding," which allows only quality tasks to be released to the field (Ballard, Howell 1998). Simultaneously, the next day's work shall be reviewed:

1) Master Schedule: One month before the start of construction, the execution budget should be fixed, and the schedule should be created considering the milestones and the budget. The master schedule should be created using the WBS linked with the

\begin{tabular}{|c|c|c|}
\hline$\frac{-1}{\frac{0}{n}}$ & $\begin{array}{l}\text { Master Schedule } \\
\text { - Retrieve the previous master } \\
\text { schedule with specific condition }\end{array}$ & $\begin{array}{ll} & \text { 4-week Look-ahead schedule } \\
\text { - Modify and develop master } \\
\text { of } \\
\text { schedule for fitting each project }\end{array}$ \\
\hline$\stackrel{2}{0}$ & $\begin{array}{l}\text { Task setting } \\
\text { - Task schedule is made from } \\
\text { detailed activity by all } \\
\text { participant }\end{array}$ & $\begin{array}{l}\text { Task meeting } \\
\text { - Daily work (task) is checked } \\
\text { and approved }\end{array}$ \\
\hline
\end{tabular}

Fig. 2. Daily work management process cost. When the schedule has been created, the planned value (PV) shall be generated. The project shall be managed using the earned-value management system (EVMS).

2) Four-Week Look-ahead Schedule: the four-week look-ahead schedule shall be updated every Friday. The master schedule contains the aggregate activities (in one- or two-month terms), while the lookahead schedule contains the detailed activities (in 21-day terms) in the master schedule.

3) Task Setting: when the detailed activities in the look-ahead schedule are fixed, the construction manager, along with the subcontractor foreman, shall determine the details of the tasks. This represents the lowest level of scheduling. Each detailed activity consists of one or more task(s). The sequences, duration, and cost weight should be determined in the task setting module, as can be seen in Figure 4. The cost weight value is used to allocate the costs of the detailed activities for different tasks. The system allows the project participants to share task information, identify schedule conflicts, and negotiate such conflicts.

When the work process has been fixed, the task schedule shall be created, as shown in Figure 5. The next work shall be set after the schedule is checked and corrected.

4) Task Meeting: scheduled meetings that were held offline shall now be held via the system. Using a PDA and a PC, the actual work done shall be entered prior to the meeting, and the task meeting shall be held in the afternoon. All the participants should be in the meeting when the present day's works are to be reviewed and the next day's works are to be set.

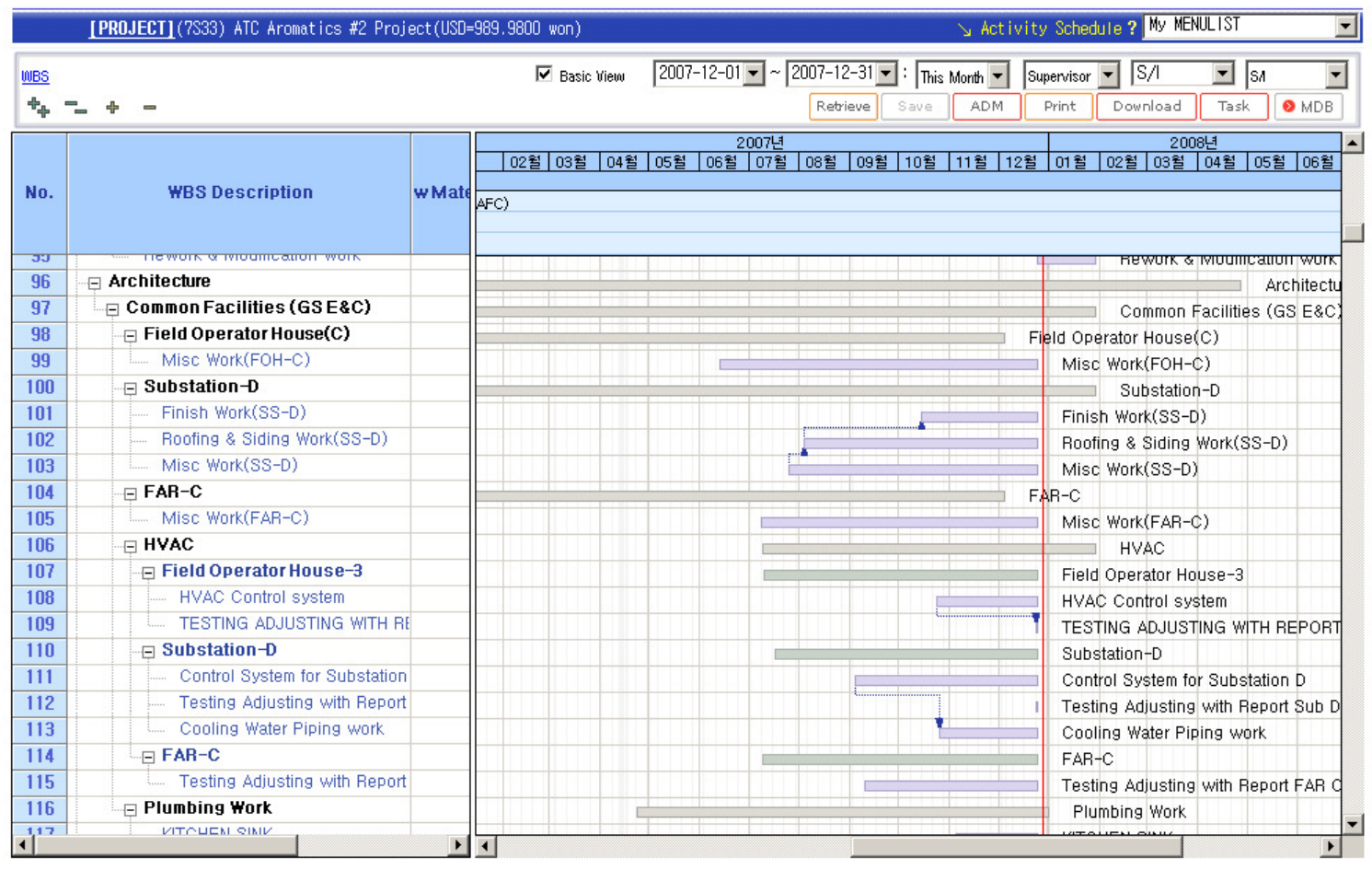

Fig. 3. Four-week look-ahead schedule 
- Setting - Scheduling Meeting 세부Acty

\begin{tabular}{|c|c|c|c|c|c|c|c|c|c|c|c|c|}
\hline \multicolumn{13}{|c|}{ VDU> VDU>Civil>Civil Common>U-Ditch>VACUUM COLUMN 북촉PIPE TRENCH (70M) } \\
\hline \multicolumn{2}{|c|}{ Lean Con'c } & \multirow{2}{*}{\multicolumn{2}{|c|}{\begin{tabular}{|c|r|} 
Footing & Re-b \\
1 & 20 \\
\end{tabular}}} & \multicolumn{2}{|c|}{ Footing Con'c } & \multicolumn{2}{|c|}{ Wall Re-bar. } & \multicolumn{2}{|c|}{ Wall Con'c } & \multicolumn{2}{|c|}{ Back Filling } & \\
\hline 1 & 10 & & & 1 & 10 & 1 & 20 & 1 & 20 & 1 & 20 & \\
\hline \multicolumn{13}{|c|}{ VDU> VDU>Civil>Civil Common>U-Ditch>U-DTCH (HEST) } \\
\hline \multicolumn{2}{|c|}{ Excavation } & \multicolumn{2}{|c|}{ Lean Con'c } & Footin & Re-b. & \multicolumn{2}{|c|}{ Footing Con' $\mathrm{C}$} & \multicolumn{2}{|c|}{ Wall Re-bar. } & \multicolumn{2}{|c|}{ Misc. Steel } & Wall $\mathrm{Co}$ \\
\hline 4 & 10 & 1 & 10 & 5 & 20 & 2 & 20 & 3 & 20 & 1 & 5 & 1 \\
\hline \multicolumn{13}{|c|}{ VDU > VDU >Civil>Civil Common>U-Ditch>u-ditch 40m(south \& east) } \\
\hline \multicolumn{2}{|c|}{ Concrete (Le..} & \multicolumn{2}{|c|}{ Footing Rebar } & & & & & & & & & \\
\hline \multirow[t]{3}{*}{1} & 10 & 2 & 10 & & & & & & & & & \\
\hline & & \multicolumn{2}{|c|}{ Footing Form } & Footin & Conc. & \multicolumn{2}{|c|}{ Curing } & & & & & \\
\hline & & 4 & 10 & 1 & 10 & 3 & 10 & & & & & \\
\hline & & & & & & & bar & & corm & & & Wall Con \\
\hline & & & & & & 2 & 10 & 1 & 10 & 1 & 10 & 1 \\
\hline
\end{tabular}

Fig. 4. Task setting

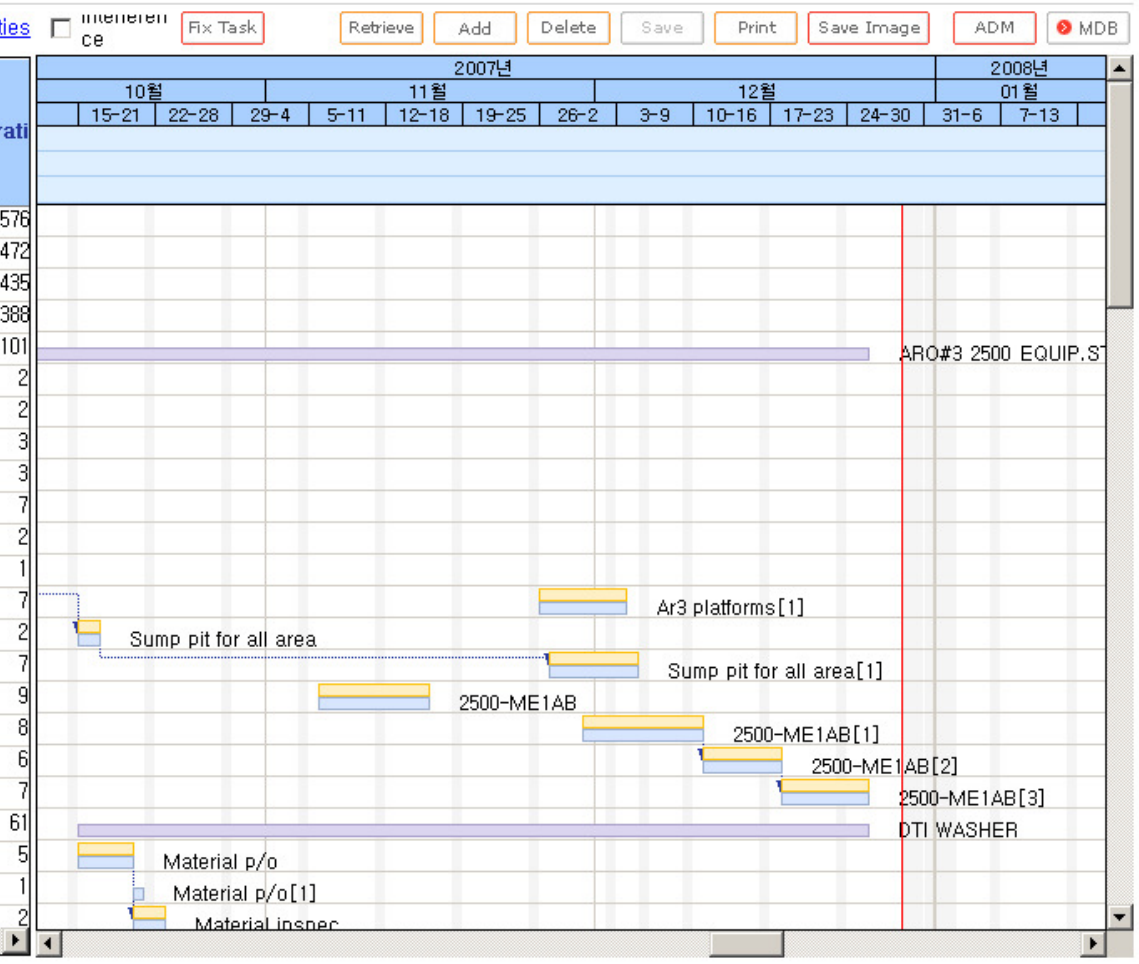

Fig. 5. Weekly schedule 


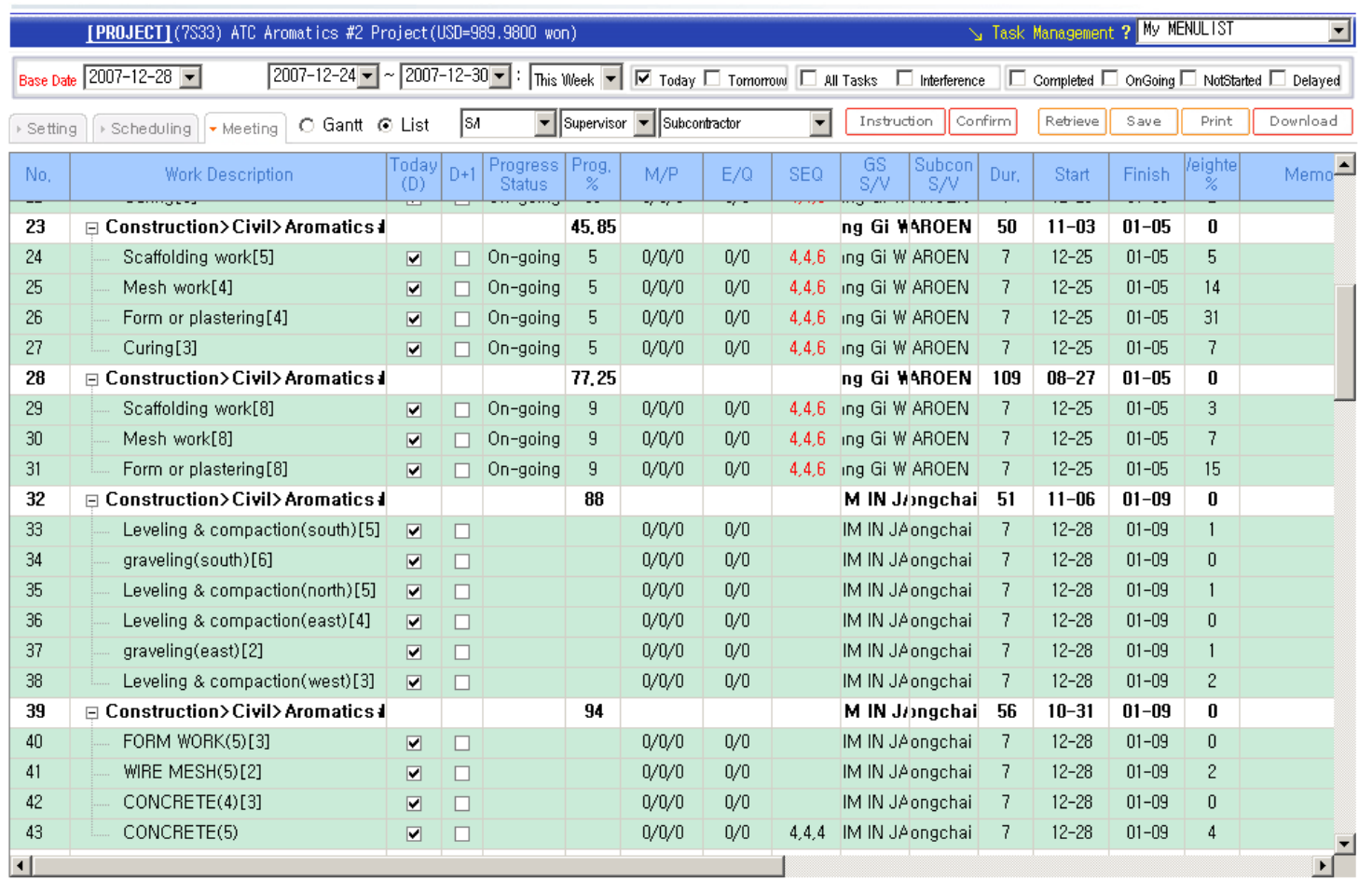

Fig. 6. Task meeting

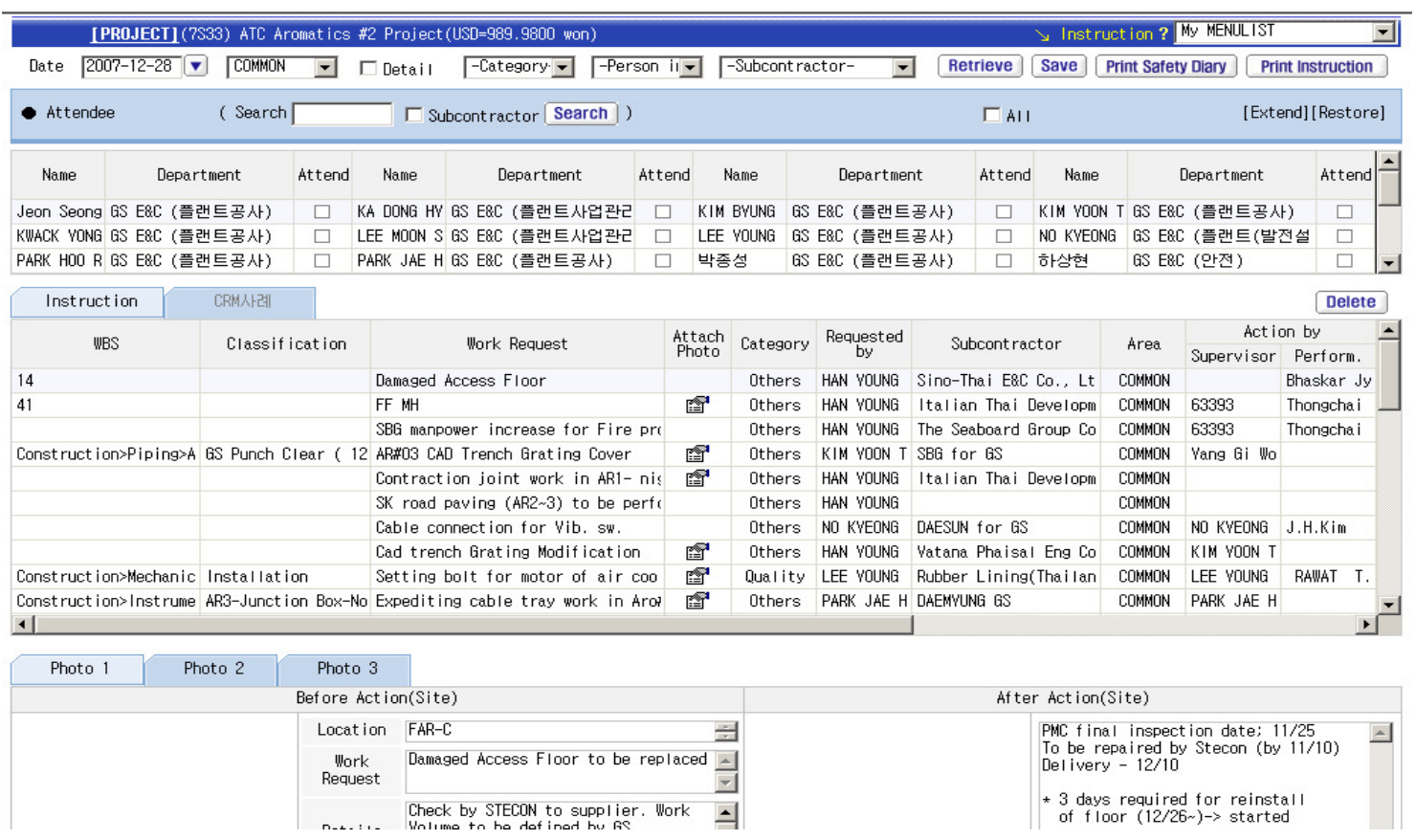

Fig. 7. Work order screen

During the daily task meeting, when the "Introduction" is selected at the top of the screen in Figure 6, the safety, quality, and environmental issues, plus the notices for the next day's work, shall be retrieved from the screen, as shown in Figure 7. The subcontractor then becomes responsible for the work in question. For ease of use, a PDA can check the work orders and results. In addition, photos can be taken and sent while notices are continually sent for uncompleted works.
5) Planning Reliability and Cause Analysis: to accurately analyze the daily work, daily planning reliability is analyzed. This involves data analysis which compares the planned works of the previous day and the actual executed works for the present day. The actual-works-to-planned-works ratio is then shown as a percentage. The system uses PPC to measure the reliability of the planning system, which is calculated as the number of completed tasks over the number of assigned tasks (Ballard 1994): 
$\mathrm{PPC}=($ No. of completed tasks / no. of assigned tasks $) \times$ $100(\%)$.

The index helps monitor how well the subcontractors keep their promises, and ensures responsibility and accountability (Ballard 2000). It is also used to evaluate the subcontractors, and the PPC data are referenced in the selection of subcontractors for future projects. The prerequisite condition in terms of the planning reliability is that a supplier's lead time should be less than the reliable look-ahead schedule length to use a pull strategy (Fig. 8).

It is hard to define the minimum PPC to qualify for pull strategy. It is more of an experimental issue rather than a mathematical issue. Since material lead time was around 7-10 days in our case study, we focused on 2-week PPC. When we investigated the pull strategy for the company, 2-week PPC was only $45-60 \%$. With the Last Planner System implemented (Ballard 2000), their 2-week PPC increased to $85-90 \%$. There was no problem in material shortage when we implemented the pull strategy.

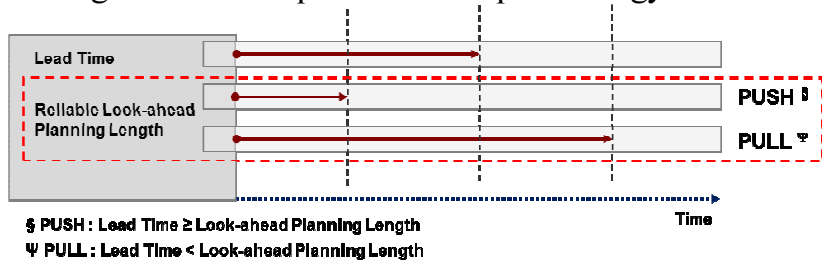

Fig. 8. Push vs pull

\section{Material management system: corresponding to the daily work management system}

Figure 10 shows the workflow in a material management system coupled with a daily work management system. The figure shows the correlation between the two systems. To reduce the material inventory onsite, engi- neered-to-order (ETO) materials are pulled from a production planning system onsite. The related works are abstracted from the four-week look-ahead schedule, which reflects the detailed activities. The delivered materials are used in the construction work according to the task schedule, and daily payment is made through the task meeting:

1) Interface between the Materials and the Schedule: the four-week look-ahead schedule becomes the basis of the procedure for requesting materials. The detailed activities in the four-week look-ahead schedule contain information on which materials are needed and how much is needed. When CBS and WBS are generated, each activity in the master schedule contains quantity take-up information, which is pulled from the bidding process $(1,2,4$, and 7 in Fig. 10).

2) Automatic Alerts: two weeks before the start of each detailed activity, the system alerts the field engineer regarding the material request for the detailed activity. Currently, the system is applied only to ETO materials with a lead time of less than 10 days (e.g. reinforced bar, curtain wall). The field engineers of a general contractor then check the quantity of materials requested and their delivery period. The task is then transferred to a material manager of a general contractor onsite, who approves it after checking the budget and size of the inventory $(7,8,9$, and 10 in Fig. 10).

3) Supply of Materials: when a material manager approves the material request, the information is sent to the related suppliers. All the suppliers who share the material procurement system with the GC are simultaneously notified. The suppliers deliver the requested materials and the delivery slip to the site,

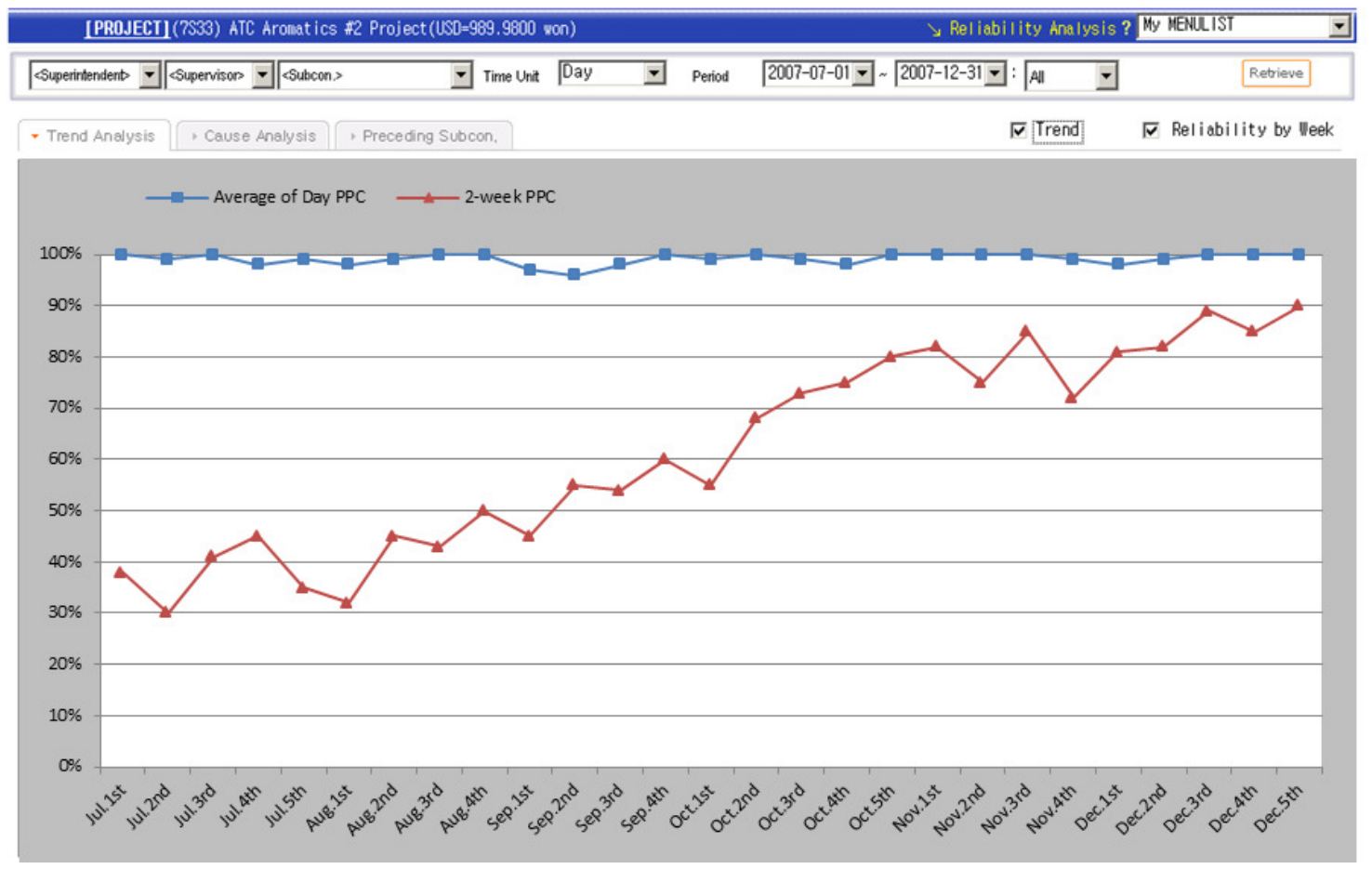

Fig. 9. Planning reliability analysis 


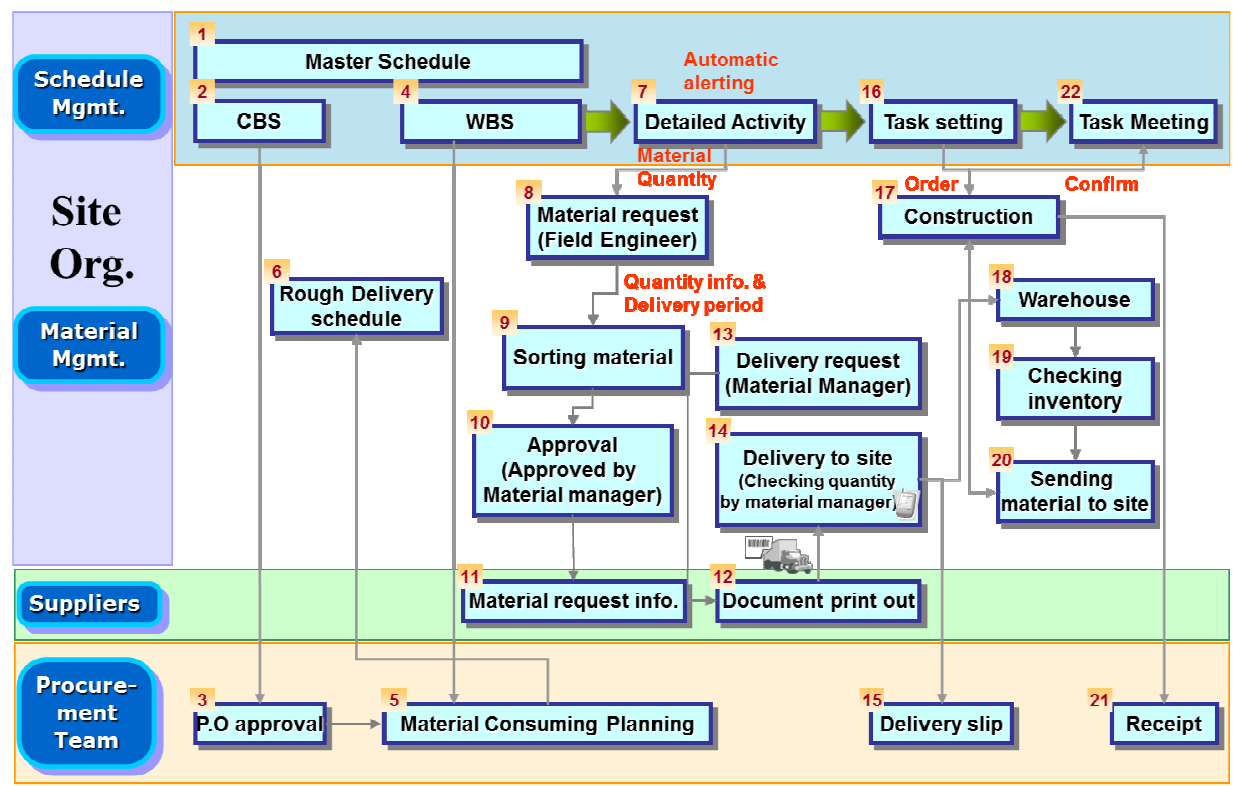

Fig. 10. System workflow

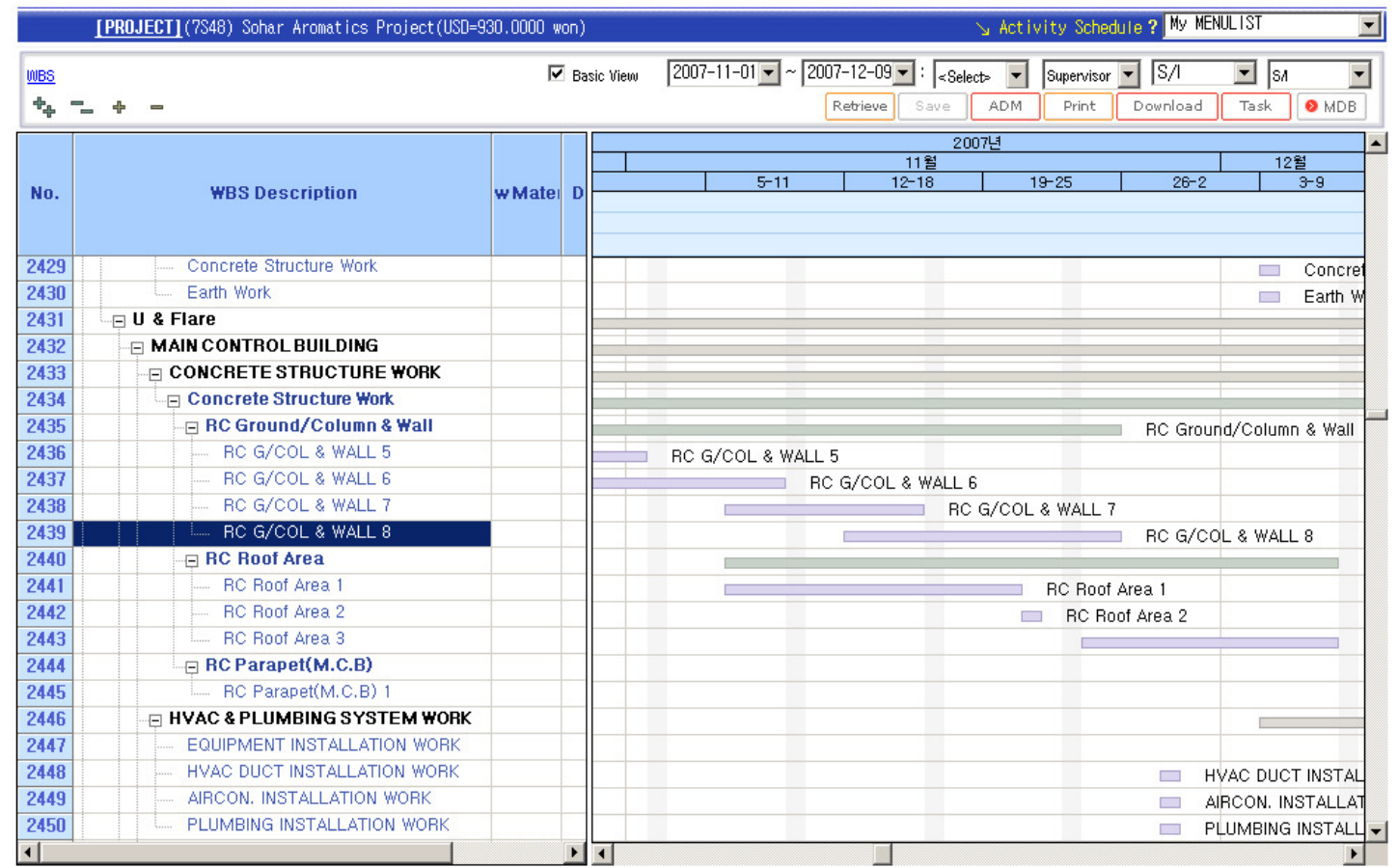

Fig. 11. Detailed activity schedule

while the material manager checks the quantity and type of the delivered materials using a PDA barcode reader. The information on materials can be retrieved by suppliers in the material procurement system. The enclosed delivery slip is sent to the procurement team at the headquarters $(11,12,13$, 14, and 15 in Fig. 10).

4) Construction: the delivered material is used in the construction phase or is stocked in a warehouse or yard. In the task meeting, the GCs and subcontractors decide which task will be accomplished the next day. The receipt slip is then sent to the procurement team at the headquarters $(16,17,18,19,20$, 21, and 22 in Fig. 10).

\section{Example: implementing a material pull from the production schedule using the proposed system}

This paper demonstrates the scheduling and material procurement system using an example. One of the detailed activities (called "Act. 1") is retrieved from the system on November 21 2007, RC G/COL \& Wall 8:

1) Material Request: If retrieved between November 5 and 21 related to Act. 1, the material list related to Act. 1 is shown below. As shown in Figure 12, Act. 1 requires three items: $285 \mathrm{~m}^{3}\left(340.9 \mathrm{yd}^{3}\right)$ ready-mix concrete (25-120-12), $10 \mathrm{~mm} 36,480 \mathrm{~kg}$

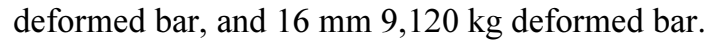


Deflu, 7548 - Sohar Aromatics Prc $\backsim$

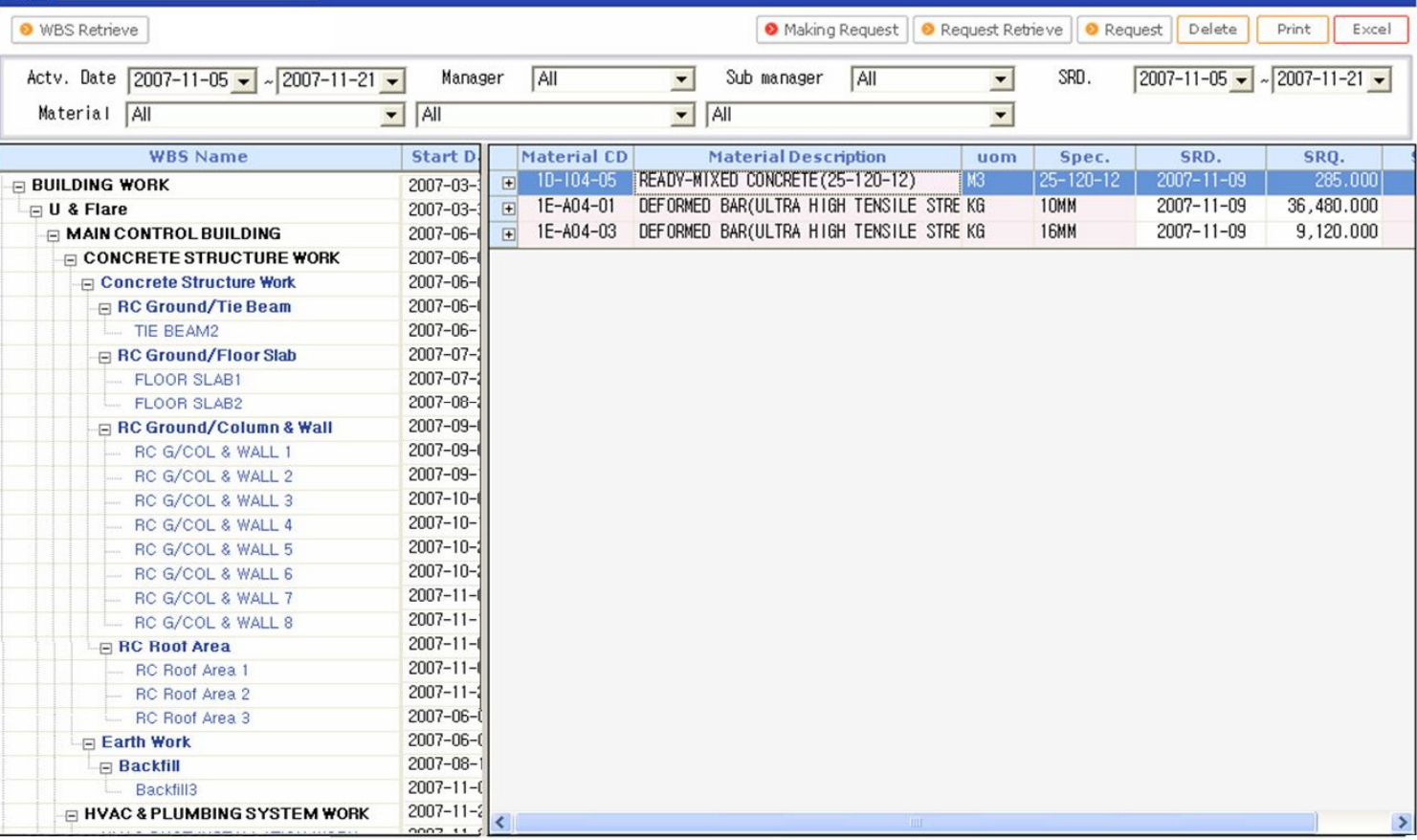

Fig. 12. Material list related to Act. 1

C6. 7948 - Soher Arontics Pre $\vee$

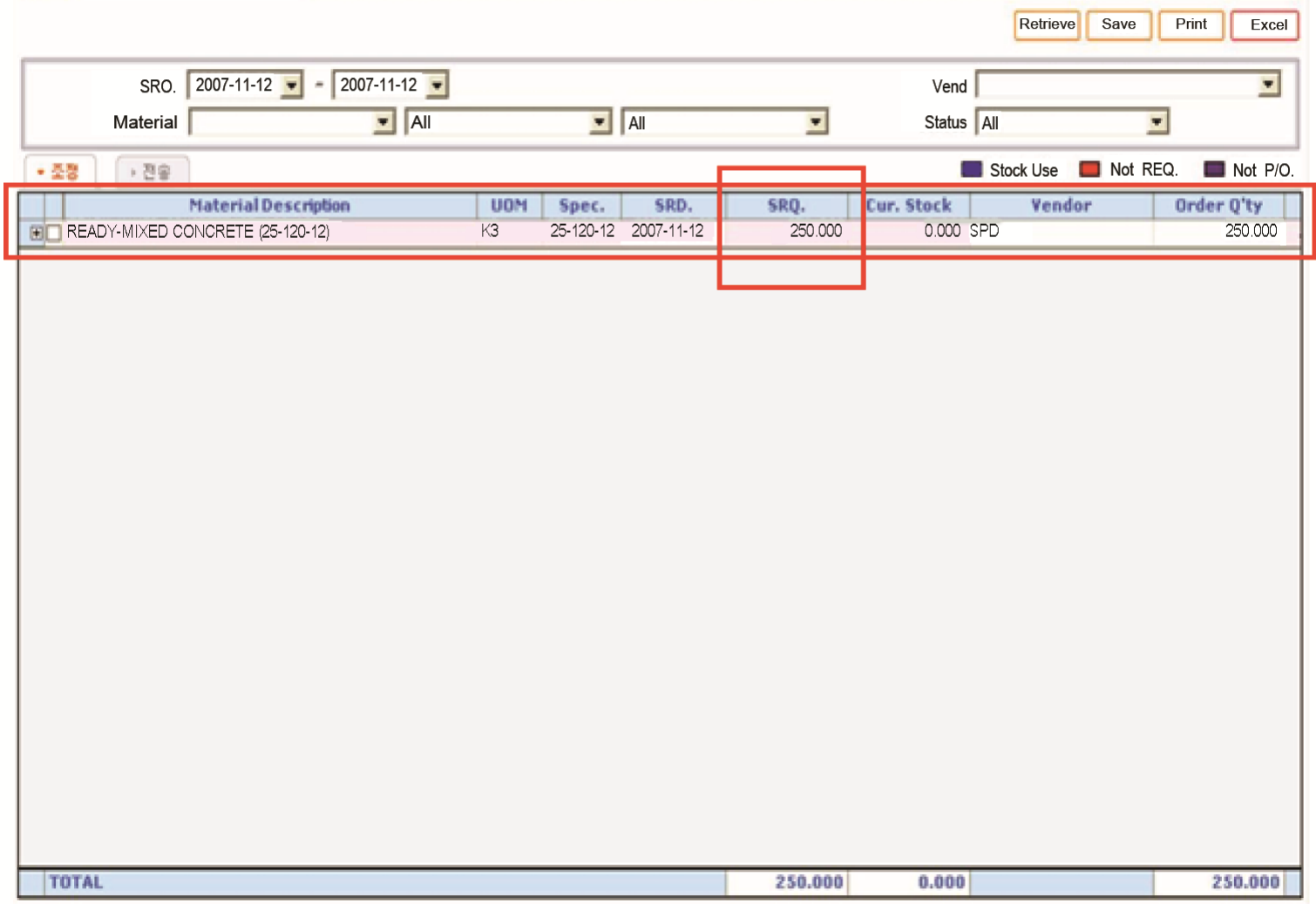

Fig. 13. Approval by the material manager 
A field engineer requests for materials after confirming that these will be used up based on the updated schedule. The material manager who receives the material request approves it, and the system automatically sends an order request to the supplier. As shown in Figure 13, the field engineer requests only for $250 \mathrm{~m}^{3}$ $\left(299.0 \mathrm{yd}^{3}\right)$ ready-mix concrete $(25-120-12)$ on November 12 .

2) Delivery to the Site: when the materials are delivered to the site, a site personnel checks the quantity and type of materials using a PDA barcode reader (Fig. 14). Then a material manager sends them to the construction site or yard. As shown in Figure 15, the requested $250 \mathrm{~m}^{2}\left(299.0 \mathrm{yd}^{2}\right)$ ready-mix cement was delivered to the site on November 20.

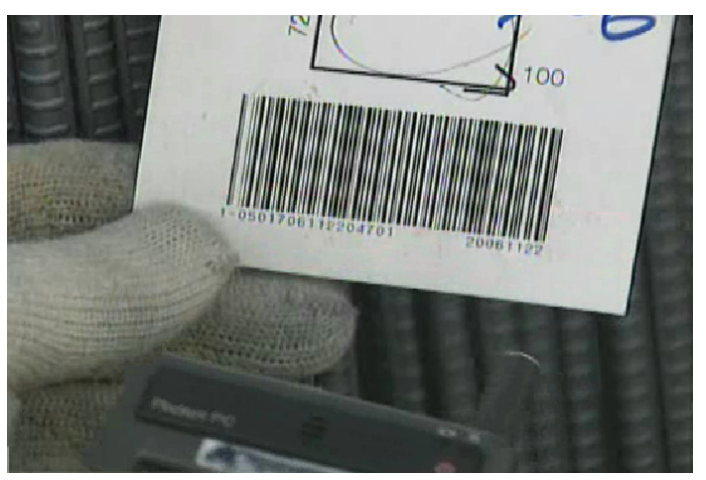

Fig. 14. Checking the materials using the PDA
3) Closing: assume that the task belonging to Act. 1 was completed. This means that the material was used in the construction work. Then in the task meeting, the GC and subcontractors confirm the task completion, and the daily payment is automatically approved. No monthly progress payment request from the subcontractor shall be required. Through this process, there is no need for several human resources in the process of progress payment. This is one example of wastage elimination by using the proposed system.

\section{Discussion}

It was difficult to validate the effectiveness of the daily material management system on a full scale. Instead, these authors conducted a survey to assess the effectiveness of the system, followed by interviews with the system users regarding the benefits and challenges of the system.

\subsection{Survey method}

These authors developed a questionnaire to identify the benefits of the proposed system. Copies of the questionnaire were distributed to the users (field engineers, material managers, and site managers in general contractor) of the proposed system. In constructing the questionnaire, the Likert scaling system was used. This five-point rating scale measured the attitude of the respondent on a continuum from highly favorable to highly unfavorable, or vice versa, with an equal number of positive and negative response possibilities and one middle or neutral response.

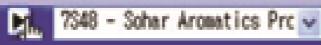

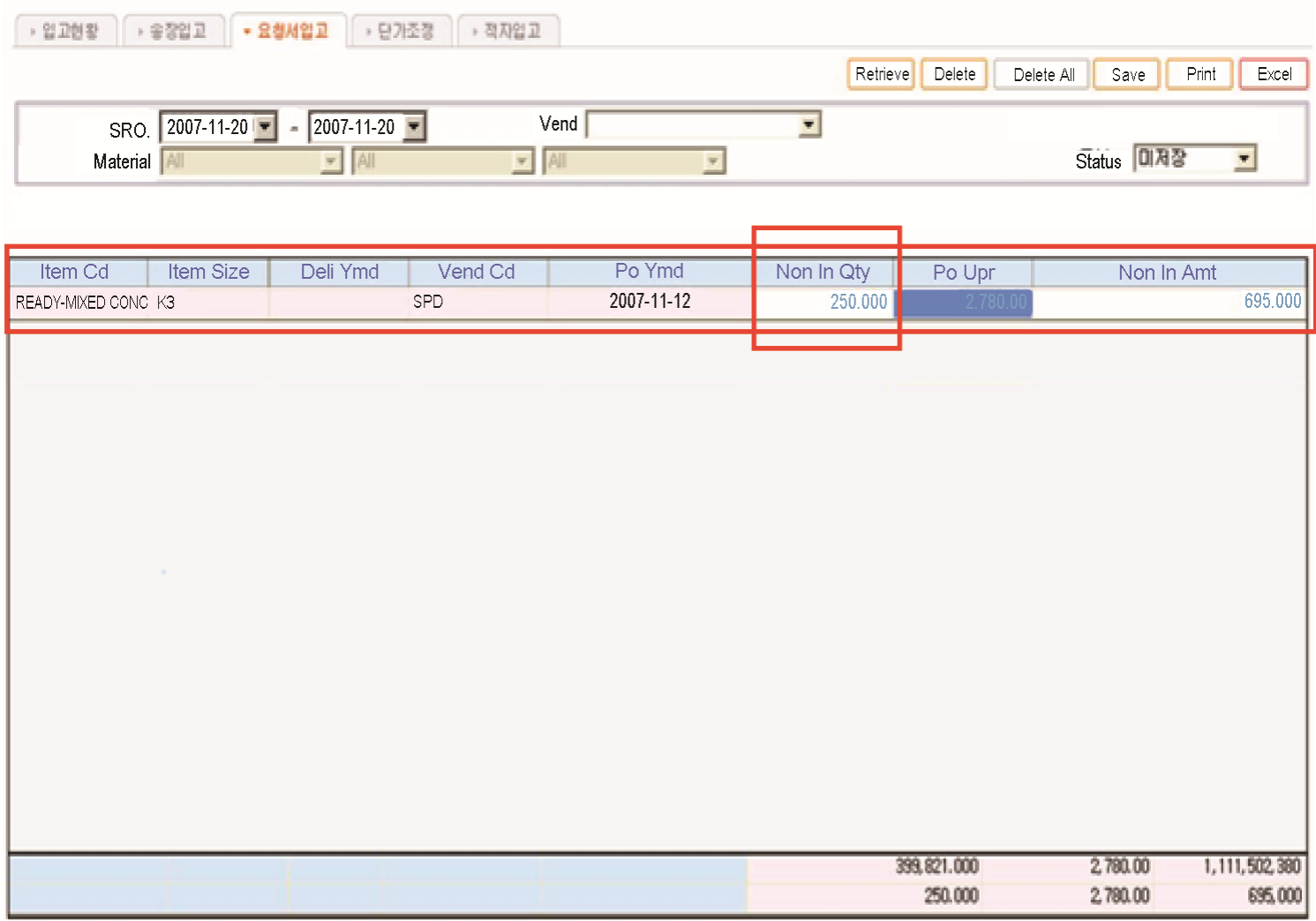

Fig. 15. Delivered-materials list from the PDA 


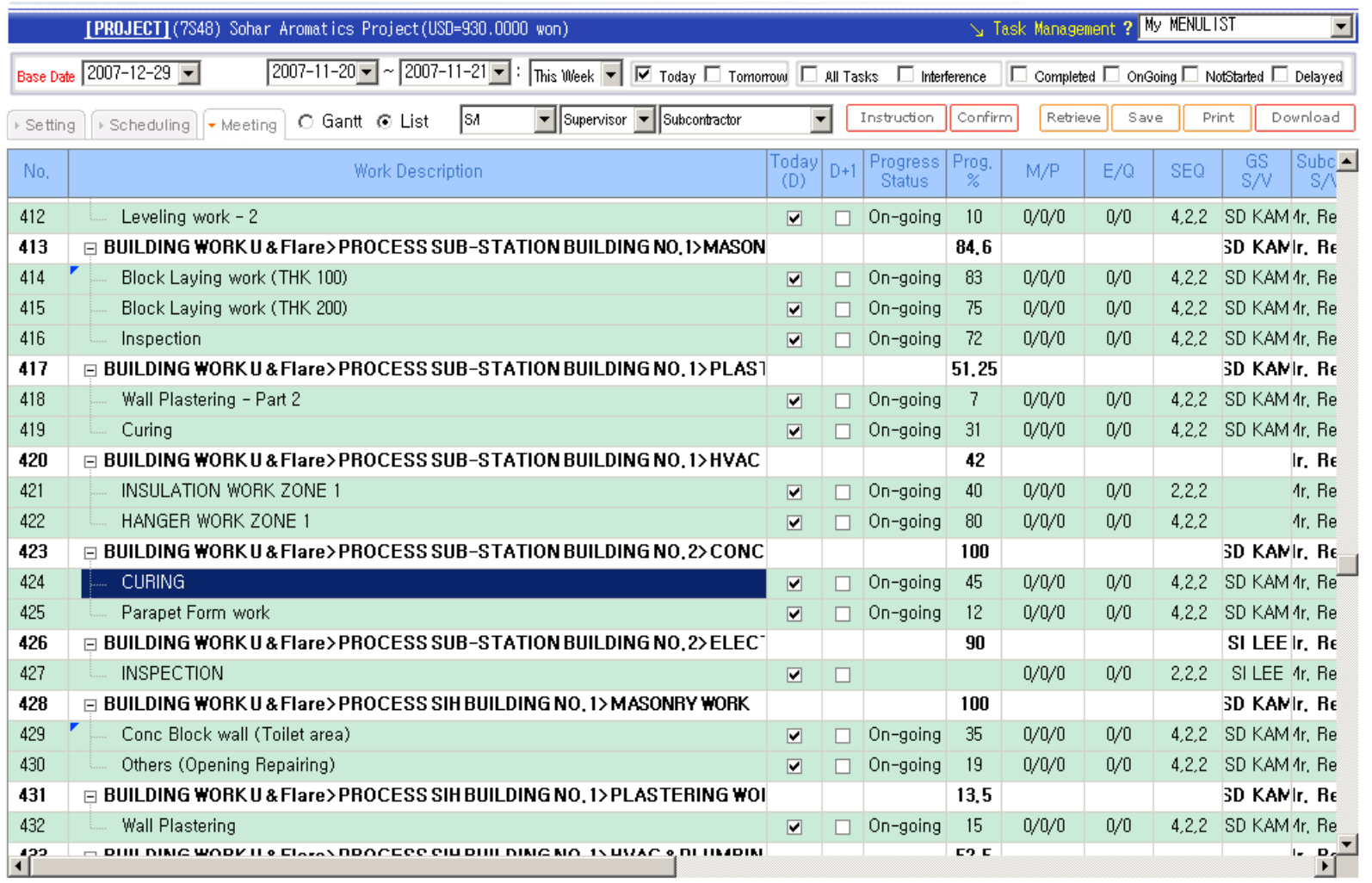

Fig. 16. Confirmation of approved tasks

The survey was conducted twice, first in April 2010 and second in October 2010. Field engineers and site managers of a general contractor who have experienced using the proposed system over 6 months (in April) and over 1 year (in October) were asked to answer the questionnaire and to provide comments. They have been involved in over 200 different construction projects (46 commercial, 83 residential, 42 civil, 21 environmental, and 14 plant projects). The demography of the respondents in each survey is presented in Table 1.

Table 1. Overview of the survey respondents

\begin{tabular}{|c|c|c|c|c|}
\hline \multirow[b]{2}{*}{ Division } & \multicolumn{2}{|c|}{$\begin{array}{c}\text { The first half of the } \\
\text { year's survey }\end{array}$} & \multicolumn{2}{|c|}{$\begin{array}{l}\text { The second half } \\
\text { year's survey }\end{array}$} \\
\hline & $\begin{array}{l}\overrightarrow{0} \\
\frac{0}{0} \\
0 \\
\tilde{0} \\
\simeq \\
\simeq\end{array}$ & 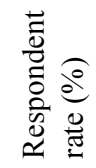 & $\begin{array}{l}\overrightarrow{0} \\
\frac{0}{0} \\
0 \\
\tilde{0} \\
\simeq\end{array}$ & 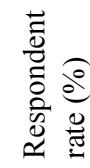 \\
\hline Architecture & 270 & 77.14 & 262 & 62.38 \\
\hline Residential & 349 & 66.73 & 349 & 63.45 \\
\hline Civil & 228 & 68.67 & 258 & 78.42 \\
\hline Environmental & 154 & 71.3 & 205 & 91.52 \\
\hline Plant & 237 & 72.7 & 319 & 94.94 \\
\hline Overall & 1238 & 70.86 & 1393 & 78.14 \\
\hline
\end{tabular}

The questions related to the system are as follows:

Example question 1: How well does the system support each function (material request, delivery request, checking inventory)?
Example question 2: How much was the workload increased/decreased compared to the past?

Example question 3: Do you agree that the proposed system will improve work efficiency if it is applied to all construction projects and their stakeholders?

Table 2 shows the survey results using the sevenpoint Likert scale, in which a score of 1 corresponds to "very easy to use" and a score of 5 represents "very difficult to use".

The survey results showed that the system was effective in material purchasing, delivery request, and checking inventory. The average score for the usability of the proposed system was 3.27-3.39 $(\mathrm{SD}=$ about 0.7$)$ in all the divisions, and the average score rose between the first and second half of the year. As for the practicality of the proposed system, the respondents replied positively (7-80\% positive responses).

With regard to the workload when using the proposed system, the average score went down in all the divisions, and the users easily adopted the system.

In the last item, the responses showed that efficiency decreased compared to the first half of the year. This can be attributed to the fact that users had then learned how to use the proposed system so their expectations decreased. Further, the users had discovered the proposed system's limitation (i.e. the users must use the system themselves so the average score went down). 
Table 2. Usability of the proposed system

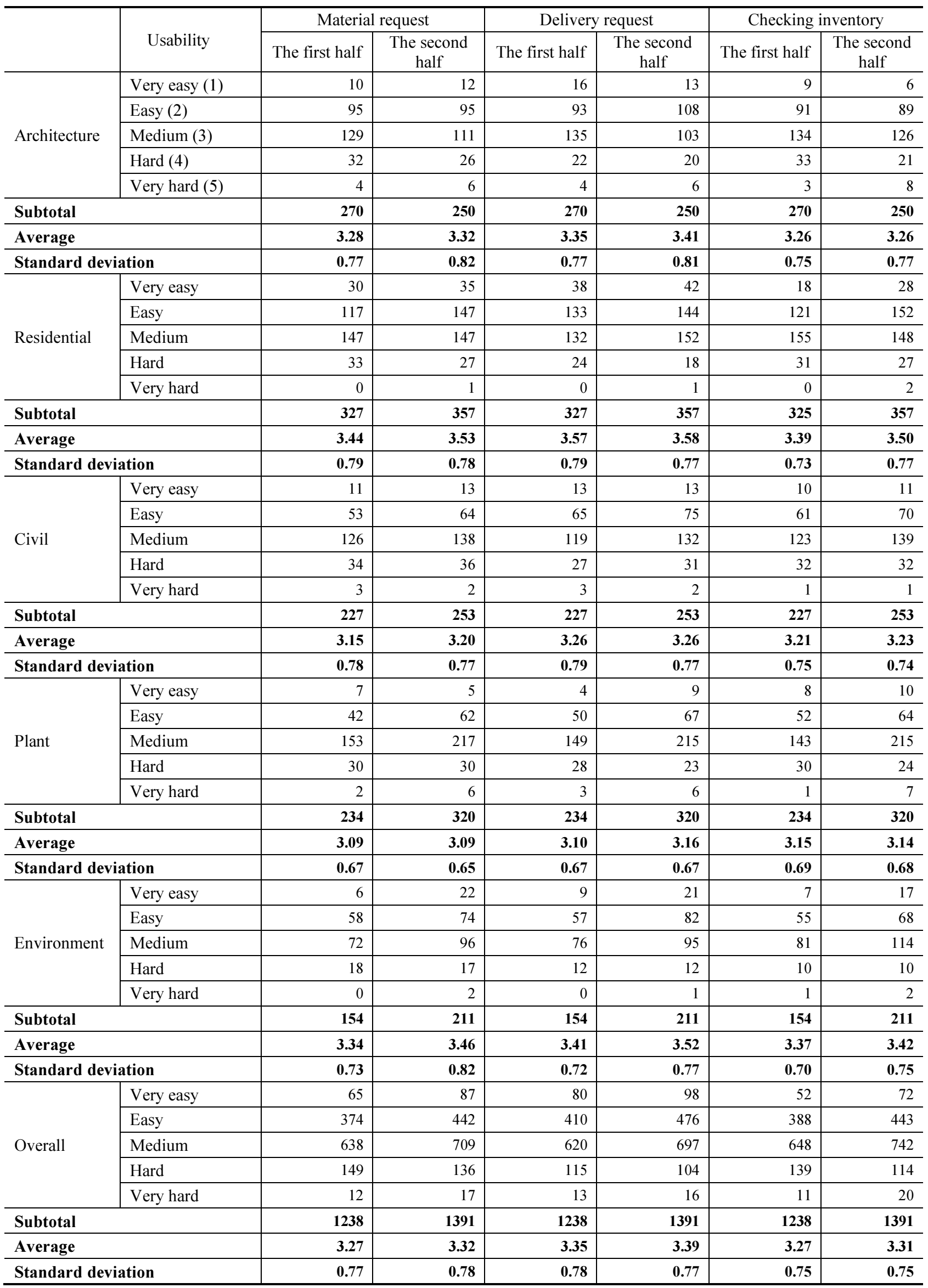


Table 3. Workload of the proposed system

\begin{tabular}{|c|c|c|c|}
\hline & & \multicolumn{2}{|c|}{ Work load } \\
\hline & & $\begin{array}{l}\text { The first } \\
\text { half }\end{array}$ & $\begin{array}{c}\text { The second } \\
\text { half }\end{array}$ \\
\hline \multirow{5}{*}{$\begin{array}{l}\text { Archi- } \\
\text { tecture }\end{array}$} & Increased a lot & 17 & 4 \\
\hline & Increased & 120 & 82 \\
\hline & Medium & 116 & 115 \\
\hline & Decreased & 16 & 20 \\
\hline & Decreased a lot & 1 & 1 \\
\hline \multicolumn{2}{|l|}{ Subtotal } & 270 & 222 \\
\hline \multicolumn{2}{|l|}{ Average } & 3.50 & 3.31 \\
\hline \multicolumn{2}{|c|}{ Standard deviation } & 0.72 & 0.68 \\
\hline \multirow{5}{*}{$\begin{array}{l}\text { Residen- } \\
\text { tial }\end{array}$} & Increased a lot & 33 & 9 \\
\hline & Increased & 144 & 106 \\
\hline & Medium & 140 & 168 \\
\hline & Decreased & 13 & 45 \\
\hline & Decreased a lot & 0 & 1 \\
\hline \multicolumn{2}{|l|}{ Subtotal } & 330 & 329 \\
\hline \multicolumn{2}{|l|}{ Average } & 3.60 & 3.23 \\
\hline \multicolumn{2}{|c|}{ Standard deviation } & 0.72 & 0.73 \\
\hline \multirow{5}{*}{ Civil } & Increased a lot & 7 & 6 \\
\hline & Increased & 80 & 39 \\
\hline & Medium & 131 & 132 \\
\hline & Decreased & 8 & 18 \\
\hline & Decreased a lot & 1 & 1 \\
\hline \multicolumn{2}{|l|}{ Subtotal } & 227 & 196 \\
\hline \multicolumn{2}{|l|}{ Average } & 3.37 & 3.16 \\
\hline \multicolumn{2}{|c|}{ Standard deviation } & 0.63 & 0.64 \\
\hline \multirow{5}{*}{ Plant } & Increased a lot & 7 & 4 \\
\hline & Increased & 65 & 42 \\
\hline & Medium & 153 & 134 \\
\hline & Decreased & 9 & 8 \\
\hline & Decreased a lot & 0 & \\
\hline \multicolumn{2}{|l|}{ Subtotal } & 234 & 188 \\
\hline \multicolumn{2}{|l|}{ Average } & 3.30 & 3.22 \\
\hline \multicolumn{2}{|c|}{ Standard deviation } & 0.59 & 0.69 \\
\hline \multirow{5}{*}{$\begin{array}{l}\text { Envi- } \\
\text { ronment }\end{array}$} & Increased a lot & 5 & 4 \\
\hline & Increased & 60 & 51 \\
\hline & Medium & 77 & 96 \\
\hline & Decreased & 12 & 20 \\
\hline & Decreased a lot & 0 & 1 \\
\hline \multicolumn{2}{|l|}{ Subtotal } & 154 & 172 \\
\hline \multicolumn{2}{|l|}{ Average } & 3.38 & 3.22 \\
\hline \multicolumn{2}{|c|}{ Standard deviation } & 0.67 & 0.69 \\
\hline \multirow{5}{*}{ Overall } & Increased a lot & 69 & 27 \\
\hline & Increased & 478 & 320 \\
\hline & Medium & 630 & 645 \\
\hline & Decreased & 59 & 111 \\
\hline & Decreased a lot & 2 & 4 \\
\hline Subtotal & & 1238 & 1107 \\
\hline Average & & 3.45 & 3.23 \\
\hline Standard & viation & 0.68 & 0.67 \\
\hline
\end{tabular}

Table 4. Efficiency of the proposed system

\begin{tabular}{|c|c|c|c|}
\hline & & \multicolumn{2}{|c|}{ Efficiency } \\
\hline & & $\begin{array}{c}\text { The first } \\
\text { half }\end{array}$ & $\begin{array}{c}\text { The second } \\
\text { half }\end{array}$ \\
\hline \multirow{5}{*}{ Architecture } & Very useful & 21 & 8 \\
\hline & Useful & 145 & 106 \\
\hline & Medium & 92 & 93 \\
\hline & Less useful & 7 & 6 \\
\hline & Not useful at all & 5 & 7 \\
\hline \multicolumn{2}{|l|}{ Subtotal } & 270 & 220 \\
\hline \multicolumn{2}{|l|}{ Average } & 3.63 & 3.46 \\
\hline \multicolumn{2}{|c|}{ Standard deviation } & 0.74 & 0.75 \\
\hline \multirow{5}{*}{ Residential } & Very useful & 33 & 11 \\
\hline & Useful & 177 & 171 \\
\hline & Medium & 109 & 123 \\
\hline & Less useful & 9 & 28 \\
\hline & Not useful at all & 0 & 2 \\
\hline \multicolumn{2}{|l|}{ Subtotal } & 328 & 335 \\
\hline \multicolumn{2}{|l|}{ Average } & 3.71 & 3.48 \\
\hline \multicolumn{2}{|c|}{ Standard deviation } & 0.68 & 0.72 \\
\hline \multirow{5}{*}{ Civil } & Very useful & 25 & 2 \\
\hline & Useful & 104 & 89 \\
\hline & Medium & 82 & 88 \\
\hline & Less useful & 11 & 13 \\
\hline & Not useful at all & 5 & 8 \\
\hline \multicolumn{2}{|l|}{ Subtotal } & 227 & 200 \\
\hline \multicolumn{2}{|l|}{ Average } & 3.59 & 3.32 . \\
\hline \multicolumn{2}{|c|}{ Standard deviation } & 0.83 & 0.78 \\
\hline \multirow{5}{*}{ Plant } & Very useful & 14 & 5 \\
\hline & Useful & 97 & 71 \\
\hline & Medium & 115 & 102 \\
\hline & Less useful & 7 & 7 \\
\hline & Not useful at all & 1 & \\
\hline \multicolumn{2}{|l|}{ Subtotal } & 234 & 185 \\
\hline \multicolumn{2}{|l|}{ Average } & 3.50 & 3.40 \\
\hline \multicolumn{2}{|c|}{ Standard deviation } & 0.67 & 0.61 \\
\hline \multirow{5}{*}{$\begin{array}{l}\text { Envi- } \\
\text { ronment }\end{array}$} & Very useful & 9 & 14 \\
\hline & Useful & 89 & 88 \\
\hline & Medium & 53 & 72 \\
\hline & Less useful & 3 & 4 \\
\hline & Not useful at all & 0 & 1 \\
\hline \multicolumn{2}{|l|}{ Subtotal } & 154 & 179 \\
\hline \multicolumn{2}{|l|}{ Average } & 3.68 & 3.61 \\
\hline \multicolumn{2}{|c|}{ Standard deviation } & 0.61 & 0.69 \\
\hline \multirow{5}{*}{ Overall } & Very useful & 103 & 40 \\
\hline & Useful & 623 & 525 \\
\hline & Medium & 461 & 478 \\
\hline & Less useful & 37 & 58 \\
\hline & Not useful at all & 14 & 18 \\
\hline Subtotal & & 1238 & 1119 \\
\hline Average & & 3.62 & 3.46 \\
\hline Standard de & iation & 0.73 & 0.72 \\
\hline
\end{tabular}


These authors received feedback from the managers, engineers and suppliers who used the proposed system. The benefits and challenges involved in using the system, based on the feedback results, are summarized as follows:

Benefits:

(1) The current weekly planning reliability, which is measured by PPC, rose to $90 \%$ from the current $60 \%$. This means that there was accurate schedule planning, which in turn led to increased productivity as a result of the accurate deployment of materials, manpower, and equipment;

(2) The reduced demand variability resulting from the increased planning reliability helped in the successful implementation of a material pull system;

(3) A material procurement system, which eliminates the manual material procurement procedures, was shared with the suppliers. It helped reduce the supplier's lead time, which also helped in the successful implementation of a material pull system;

(4) A material pull system enabled the GC to reduce the material inventories onsite. For example, the rebar inventories onsite decreased by up to $70 \%$;

(5) If the task's completion status is fixed during a daily task meeting, the payment is automatically calculated according to the actual work done. The construction progress status, revenue, and profit/loss information can be viewed in real time. This ensures transparency in cost management.

\section{Challenges:}

(1) Some employees feel that they are overloaded with work with the proposed system;

(2) Some subcontractors do not have the capability to use the proposed system, which means that not many people are accustomed to the computer and to the proposed system's software;

(3) Some projects with second- or third-tier subcontracts showed difficulty in implementing the proposed system. As the GC did not have direct control over the second-tier subcontractors, they had difficulties communicating the production plans. This matter is critical in lean production control.

Table 5. Advantages and disadvantages of using the proposed system

\begin{tabular}{cl|l}
\hline No. & \multicolumn{1}{c|}{ Advantage } & \multicolumn{1}{c}{ Disadvantage } \\
\hline 1 & $\begin{array}{l}\text { Enhancing accurate } \\
\text { schedule planning } \\
\text { ability and productivity }\end{array}$ & Overloaded work \\
\hline 2 & $\begin{array}{l}\text { Reduced demand vari- } \\
\text { ability resulting }\end{array}$ & $\begin{array}{l}\text { Difficult use, because of } \\
\text { lack of capability in com- } \\
\text { puter system }\end{array}$ \\
\hline 3 & $\begin{array}{l}\text { Reducing the suppli- } \\
\text { er's lead time }\end{array}$ & $\begin{array}{l}\text { Some projects with second } \\
\text { or third-tiered subcontracts } \\
\text { showed the difficulties in } \\
\text { implementation }\end{array}$ \\
\hline 4 & $\begin{array}{l}\text { Reducing material } \\
\text { inventories on sites }\end{array}$ & $\begin{array}{l}\text { Too many information, it is } \\
\text { hard to find the exact one }\end{array}$ \\
\hline 5 & $\begin{array}{l}\text { Ensuring transparency } \\
\text { in cost management }\end{array}$ & \multicolumn{1}{c}{-} \\
\hline
\end{tabular}

The experiences in applying the proposed system revealed that collaboration with the suppliers and subcontractors is critical. Collaboration requires not only the right attitude but also capability. The GCs spent their resources to educate the suppliers and subcontractors in order to build their capability to efficiently implement the proposed system. In the course of doing so, the GCs formed a partnership with the preferred suppliers and subcontractors.

\section{Conclusions}

Materials and purchased components account for $60-70 \%$ of the building costs, while material costs account for over $50 \%$. Therefore, the right material production planning and a low-level material inventory are essential, and both of these are linked to schedule management. This paper introduced a computerized integrated project management system and illustrated how a material pull system can be implemented using the material procurement system, which was integrated into the daily work system. The proposed system aims to improve the workflow reliability as measured via PPC, and to reduce the material inventories onsite using a material pull system.

A pilot project was implemented to test the proposed system. The pilot test demonstrated how the proposed system will operate in the field. To validate the proposed system's usability, a survey was conducted among the system users including field engineers and site managers.

The usability of the proposed system was proven to be high, and it was found to be capable of decreasing the workload. However, the users' expectations slightly decreased while using the system.

Through interviews with the system users, it was found that the proposed system enhanced their accurateschedule-planning ability and productivity. It also reduced the resulting demand variability, the supplier's lead time, and the material inventories. Work overload, however, and lack of capability in the use of computers surfaced as problems. The proposed system facilitates a material pull system but also requires collaboration with the suppliers and subcontractors.

We expect that the quality of material procurement process will be improved by more reliable planning of daily work through the suggested system in collaboration with subcontractors and suppliers. In the long run, the suggested process and system can contribute to improving production control in the material ordering system interfaced with the production planning system.

\section{References}

Arbulu, R.; Ballard, G.; Harper, N. 2003. Kanban in Construction, in Proc. of the $11^{\text {th }}$ Conference of the International Group for Lean Construction, 22-24 July 2003, Virginia Tech., Blacksburg, VA, 350-361.

Asplund, E.; Danielson, U. 1991. Rata ut byggsvagen, Svenskabyggbranschens utveckhngsfond (SBUF), Stockholm, Sweden.

Ballard, G.; Kim, Y. 2007. Implementing lean on capital projects, in Proc. of the $15^{\text {th }}$ Annual Conference of the International Group for Lean Construction, 18-20 July 2007, Detroit, MI, 88-97. 
Ballard, G. 1994. The last planner, in Proc. of the Northern California Construction Institute, 22-24 April 1994, Monterey, California. $8 \mathrm{p}$.

Ballard, G. 2000. The last planner system of production control. PhD Thesis. School of Civil Engineering, Faculty of Engineering, The University of Birmingham, UK.

Ballard, G. 2002. Managing work flow on design projects: a case study, Engineering Construction and Architectural Management 9(3): 284-291. http://dx.doi.org/10.1108/eb021223

Ballard, G.; Howell, G. 1998. Shielding production: an essential step in production control, Journal of Construction Engineering and Management 124(1): 11-17. http://dx.doi.org/10.1061/(ASCE)0733-9364(1998)124:1(11)

Ballard, G.; Kim, Y.; Jang, J.; Liu, M. 2007. Lean implementation at project level. A Research Report RR-234 to the Construction Industry Institute, September. 250 p.

Bertrand, J. W. M.; Wortmann, J. C.; Wijngaard, J. 1990. Production control: a structural and design oriented approach. Amsterdam: Elsevier. 316 p.

Forrester, J. W.; Senge, P. M. 2001. Tests for building confidence in system dynamics models, in TIMS studies in the management sciences 14. New York: North-Holland Publishing Company, 155-164.

Gonzalez, V.; Alarcon, L. F.; Mundaca, F. 2008. Investigating the relationship between planning reliability and project performance, Production Planning \& Control 19(5): 461474. http://dx.doi.org/10.1080/09537280802059023

Haas, C. T.; O'Connor, J. T.; Tucker, R. T.; Eickmann, J. A.; Fagerlund, W. R. 2000. Prefabrication and preassembly trends and effects on the construction workforce. Rep. No. 14, Center for Construction Industry Studies, Austin, Tex. $35 \mathrm{p}$.

Hopp, W.; Spearman, M. 1996. Factory physics: foundations of manufacturing management. Boston, Massachusetts: Irwin/McGraw-Hill. 720 p.

Jang, W.; Skibniewski, M. J. 2008. A wireless network system for automated tracking of construction materials on project sites, Journal of Civil Engineering and Management 14(1): 11-19. http://dx.doi.org/10.3846/1392-3730.2008.14.11-19

Kim, C.; Kim, H.; Ryu, J.; Kim, C. 2011. Ubiquitous sensor network for construction material monitoring, Journal Construction Engineering and Management 137(2): 158165. http://dx.doi.org/10.1061/(ASCE)CO.1943-7862.0000257

Kim, Y.; Ballard G.; Park, C. 2007. A case of lean implementation: shift from lean production to lean supply chain management, in Proc. of the $15^{\text {th }}$ Annual Conference of the International Group for Lean Construction, 18-20 July 2007, Detroit, MI, 129-134.
Kim, Y.; Ballard, G. 2011. Management thinking in the earned value method system and the last planner system, Journal of Management in Engineering 26(4): 223-228. http://dx.doi.org/10.1061/(ASCE)ME.1943-5479.0000026

Lean Construction Institute. 2011. [online], [cited 15 July 2011]. Available from Internet: http://www.leanconstruction.org

Liu, M.; Ballard, G.; Ibbs, W. 2011. Work flow variation and labor productivity, Journal of Management in Engineering 27(4): 236-242. http://dx.doi.org/10.1061/(ASCE)ME.1943-5479.0000056

Moon, S.; Yang, B. 2010. Effective monitoring of the concrete pouring operation in an RFID-based environment, Journal of Computing in Civil Engineering 24(1): 108-116. http://dx.doi.org/10.1061/(ASCE)CP.1943-5487.0000004

Pan, N.; Lee, M.; Chen, S. 2011. Construction material supply chain process analysis and optimization, Journal of Civil Engineering and Management 17(3): 357-370. http://dx.doi.org/10.3846/13923730.2011.594221

Paulson, B. 1995. Computers and construction - midcareer reflections, Journal of Construction Engineering and Management 121(2): 197-200.

http://dx.doi.org/10.1061/(ASCE)07339364(1995)121:2(197)

Pserng, H.; Yin, S.; Li, S. 2006. Developing a resource supply chain planning system for construction projects, Journal of Construction Engineering and Management 132(4): 393-407. http://dx.doi.org/10.1061/(ASCE)0733-9364(2006)132:4(393)

Sacks, R.; Treckmann, M.; Rozenfeld, O. 2009. Visualization of work flow to support lean construction, Journal of Construction Engineering and Management 135(12): 13071315. http://dx.doi.org/10.1061/(ASCE)CO.1943-7862.0000102

Sobotka, A.; Czarnigowska, A. 2005. Analysis of supply system models for planning construction project logistics, Journal of Civil Engineering and Management 11(1): 73-82.

Thomas, H.; Horman, M. 2006. Fundamental principles of workforce management, Journal of Construction Engineering and Management 132(1): 97-104. http://dx.doi.org/10.1061/(ASCE)0733-9364(2006)132:1(97)

Tommelein, I. 1998. Pull-driven scheduling for pipe spool installation, Journal of Construction Engineering and Management, 124(4): 279-288.

http://dx.doi.org/10.1061/(ASCE)0733-9364(1998)124:4(279)

Wegelius-Lehtonen, T.; Pahkala, S. 1998. Developing material delivery processes in cooperation: an application example of the construction industry, International Journal of Production Economics 56-57: 689-698. http://dx.doi.org/10.1016/S0925-5273(98)00077-2

Sang-Chul KIM. Assistant Professor at the Department of Architectural Engineering, Hanbat National University, Daejeon, South Korea. He is a member of Korea Institute of Construction Engineering and Management (KICEM). His research interests are earned value and its application to construction field, construction management system to fit to construction employees. Nowadays, he has studied the relationship between earned value and lean construction principle.

Yong-Woo KIM. Associate Professor, P. D. Koon Endowed Professor of Construction Management, College of Built Environments, University of Washington, Seattle, WA, USA. His research interests include lean construction and construction supply chain management. 